\title{
THE PRO-INFLAMMATORY ROLE OF MICRORNA-29b IN DIABETIC NEPHROPATHY
}

\author{
NAWAL KHINTEEL JABBAR ${ }^{1}$, ANWARA JASIB THAABAN ALMZAIEL ${ }^{2 *}$, FERDOUS ABASS JABER ${ }^{2}$ \\ ${ }^{1}$ Department of Chemistry, College of Science, University of AL-Qadisiyah, AL-Diwaniyah, Iraq. ${ }^{2}$ Department of Medical Chemistry, College \\ of Medicine, University of AL-Qadisiyah, AL-Diwaniyah, Iraq. Email: anwar.almzaiel@qu.edu.iq
}

Received: 08 August 2019, Revised and Accepted: 30 August 2019

ABSTRACT

Objectives: The objective of the study was to investigate the expression pattern of microRNA-29b (miRNA-29b) in patients with diabetic nephropathy (DN) compared to Type 2 diabetes mellitus (T2DM) and healthy subjects.

Methods: Blood samples were obtained from 30 patients with DN, 30 patients with T2DM and 30 healthy subjects as controls. Serum reactive oxygen species (ROS) and interleukine-10 (IL-10) level were measured by enzyme-linked immunosorbent assay, and quantitative polymerase chain reaction was employed to screen the expression of serum miRNA-29b and anti-apoptotic B-cell lymphoma 2 (Bcl-2).

Results: The results showed a significant increase in ROS levels $(\mathrm{p}<0.05)$ in DN group compared with T2DM and control groups. IL-10 levels were significantly increased compared to other groups $(\mathrm{p}<0.05)$. The gene expression of miRNA-29b was significantly increased with downregulation of Bcl-2 ( $\mathrm{p}<0.05)$ in DN compared to T2DM and control groups ( $\mathrm{p}<0.05)$.

Conclusions: The study suggested that miRNA-29b expression is involved in the pathogenesis of DN. Hyperglycemia induced oxidative stressmediated apoptosis, and an increase in expression of pro-inflammatory miRNA-29b exerts anti-protective effect by upregulating target genes related to inflammation and apoptosis, taken together, the results identify the regulatory role of miRNA-29b in DN.

Keywords: Diabetic nephropathy, Inflammation, miRNA, Oxidative stress, Apoptosis.

(c) 2019 The Authors. Published by Innovare Academic Sciences Pvt Ltd. This is an open access article under the CC BY license (http://creativecommons. org/licenses/by/4. 0/) DOI: http://dx.doi.org/10.22159/ajpcr.2019.v12i10.34766

\section{INTRODUCTION}

Diabetic nephropathy (DN) is the most common and prevalent macrovascular complication of both Type 1 diabetes mellitus (T1DM) and Type 2 diabetes mellitus (T2DM) [1,2], which is characterized by the presence of trace albuminuria followed by a diminished glomerular filtration rate [3]

The mechanism involved in the pathogenesis of DN still unclear. There is growing evidence support that is DN mainly a chronic inflammatory process, and increasing numbers of inflammatory mediators have been shown to play key roles in its development [4]. Interleukin (IL)-10 is cytokine with potent anti-inflammatory properties that have a key role in limiting inflammation in T2DM due to its humoral immune responses and inhibition of pancreatic $\beta$-cells destruction [5]. Apoptosis plays a crucial role in diabetic complications [6]. In DN, oxidative stress caused an increase in apoptotic Bax protein expression, with downregulation of Bcl-2 expression [7], which led to unbalance in the interaction between pro-apoptotic and anti-apoptotic Bcl-2 family members [8] and loss of normal kidney cells by excessive apoptosis and progression of renal fibrosis [9]. MicroRNA (miRNAs) is a type of, non-coding RNA, about 21-23 nucleotides in length, which modulate the gene expression at the post-transcriptional level. It has been demonstrated that miRNAs contributed to a variety of physiological and pathological process including angiogenesis, inflammation, and oxidative stress in T1DM and T2DM [10-12].

Several studies suggested that miRNA-29b is involved in the pathogenesis of diabetes and its complications $[13,14]$. There are, however, limited data on the relationship of miR-29b expression with $\mathrm{DN}$. The present study was designed to investigate miR-29b effects on the inflammatory response and apoptosis as an alternative biomarker for DN.

\section{METHODS}

\section{Patients and samples}

This study including blood samples and experiment protocols was approved by the Ethical Committee of Al-Diwaniyah Teaching Hospital and College of Medicine University of Al-Qadisiyah. In addition, informed consent was obtained from all study participants before sample collection. The blood samples were obtained from 90 subjects who attended to Al-Diwaniyah hospital, between October 2017 and August 2018. Subjects were categorized accordingly into three groups: 30 patients with T2DM patients ([12 male, 18 female], 30 patients with DN patients [14 male, 16 female] and 30 normal healthy subjects [15 male, 15 female]) as control group. The mean ages of patients group with T2DM, DN and controls are: $(54.7 \pm 12.5 ; 56.6 \pm 12.4$; and $52.9 \pm 11.1$; $15)$ respectively. Control group subjects who were confirmed to be normotensive and without any chronic disease, such as DM, kidney diseases or other serious diseases were chosen. All laboratory tests analysis was performed in Diwaniyah Teaching Hospital and the medical Chemistry Research Lab, College of Medicine, University of Al-Qadisiyah.

\section{Methods}

A blood sample $(5 \mathrm{ml})$ was taken from all study groups. The blood $(1 \mathrm{ml})$ was then immediately put in dipotassium-EDTA Vacutainer ${ }^{\circledR}$ tubes and kept until analysis for mRNA Bcl-2 by quantitative polymerase chain reaction (qPCR) technique, $4 \mathrm{ml}$ of blood was allowed to clot for $20 \mathrm{~min}$, then serum was separated by centrifugation at $4000 \mathrm{rpm}$ for $15-20 \mathrm{~min}$ at $4^{\circ} \mathrm{C}$. The separated serum was divided into two parts using Eppendorf tubes $(0.3 \mathrm{ml})$ one part kept at $-80^{\circ} \mathrm{C}$ for miRNA29b analysis, while the other was kept at $-20^{\circ} \mathrm{C}$ for biochemical analysis. Fasting blood sugar, hemoglobin $\mathrm{A} 1 \mathrm{c}(\mathrm{HbA1c})$, the serum $\mathrm{Cr}$, BU, and albumin (Alb) were determined by routine techniques using an automated analyzer (Abbott, USA) from Al-Diwaniyah Teaching Hospital. Reactive oxygen species (ROS) and IL-10 were measured by enzyme-linked immunosorbent 
assay, while qPCR was employed to determine the serum level expression of miRNA-29b. $200 \mu \mathrm{l}$ of serum was used for extraction of miRNA using Serum/Plasma miRNA purification kit (BioWorld, USA). The cDNA was prepared from miRNA with Poly Polymerase (A) tailing using the miRNA cDNA synthesis kit (ABM, Canada). Then, the PCR was conducted using cDNA BrightGreen master mix for miRNA qPCR (ABM, Canada). Forward and reverse universal primers for miRNA were used.

\section{Statistical analysis}

Data are expressed as mean \pm standard error of mean. Statistical analyses were conducted with SPSS 24.0 software, one-way ANOVA, followed by the Tukey post hoc analysis or a non-parametric ranking (Kruskal-Wallis) were carried out as appropriate to compare multiple groups for normal and non-normal distribution data, respectively. $\mathrm{p}<0.05$ was considered significant throughout.

\section{RESULTS}

A total of 60 patients and 30 normal control subjects were enrolled in the present study. The patient's characteristics and biochemical serum assays are shown in Table 1.

DN analysis compared with the T2DM patients and the control, the HbA1c levels were significantly higher in DN ( $<<0.05)$. Blood pressure was higher in patients with DN compared to T2DM and control groups $(\mathrm{p} \leq 0.05)$. A significant increase was found in serum $\mathrm{Cr}$, BU, while Alb level was decreased $(\mathrm{p} \leq 0.05)$ in DN compared to T2DM and control groups.

Serum ROS levels were significantly increased in the DN compared to T2DM and control groups ( $<<0.05$, Fig. 1). However, their levels were none significantly decrease in T2DM group compared to the control group, as shown in Fig. 1.

Serum IL-10 level was significantly increase in DN and T2DM groups compared to the control group ( $\mathrm{p}<0.05$, Fig. 2).

According to qPCR data, the expression of anti-apoptotic Bcl-2 is significantly decrease in patients with T2DM and DN compared to control ( $\mathrm{p}<0.05$, Fig. 3).

A significant increase was indicated in serum levels of miRNA-29b expression in patients with T2DM and DN compared to control $(p<0.05$, Fig. 4). miRNA-29b levels were negatively correlated with the levels of Bcl-2 ( $r=-0.568, p<0.05$, Fig. 5).

\section{DISCUSSION}

The biological functions of miRNAs in the progression of DN are becoming recognized, and there is increasing interest in identifying the key miRNAs involved in the pathogenesis of DN to develop efficient therapeutic targets. The finding of present indicated an increase in the serum ROS level in DN group compared to T2DM and control groups.

Table 1: Comparison of the clinical, biochemical, and hemodynamic variables study groups

\begin{tabular}{llll}
\hline Variables & Control group & T2DM group & DN group \\
\hline FBS (mg/dl) & $93.96 \pm 5.48$ & $233.03 \pm 81.15^{*}$ & $244.3 \pm 61.80^{*}$ \\
$\mathrm{HbA} 1 \mathrm{c}(\%)$ & $4.82 \pm 0.49$ & $7.13 \pm 1.09^{*}$ & $9.72 \pm 1.36^{*}$ \\
$\mathrm{SBP}(\mathrm{mmHg})$ & $121.0 \pm 11.3$ & $128.0 \pm 17.3$ & $141.9 \pm 26.9^{*}$ \\
$\mathrm{DBP}(\mathrm{mmHg})$ & $78.4 \pm 1.3$ & $89.7 \pm 1.7$ & $99.7 \pm 21.4^{*}$ \\
$\mathrm{Cr}(\mathrm{mg} / \mathrm{dl})$ & $0.57 \pm 0.26$ & $0.85 \pm 0.24$ & $4.91 \pm 2.02^{*}$ \\
$\mathrm{BU}(\mathrm{mg} / \mathrm{dl})$ & $23.23 \pm 6.14$ & $29 \pm 4.18$ & $92.03 \pm 22.33^{*}$ \\
$\mathrm{Alb}(\mathrm{mg} / \mathrm{dl})$ & $4.29 \pm 0.52$ & $4.18 \pm 0.42$ & $2.38 \pm 0.34^{*}$ \\
\hline
\end{tabular}

*indicates significant differences compared to the control," significant differences between patient groups $(\mathrm{p} \leq 0.05)$. FBS: Fasting blood sugar, HbA1c: Hemoglobin A1c, SBP: Systolic blood pressure, DBP: Diastolic blood pressure, BU: Blood urea (BU), Cr: Creatinine, Alb: Albumin

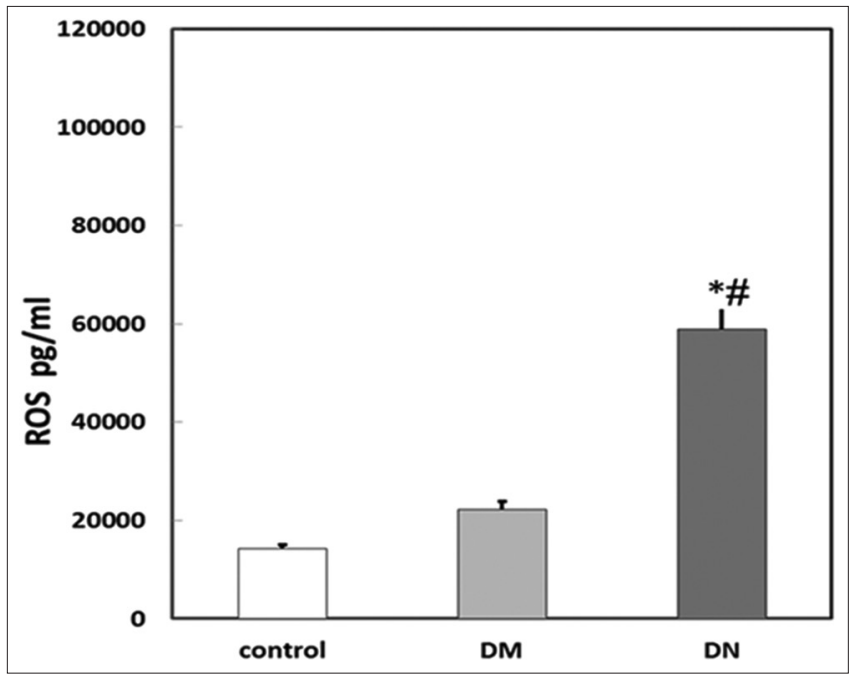

Fig. 1: Reactive oxygen species level in serum patients with type 2 diabetic, diabetic nephropathy, and control groups. Data are expressed as means \pm standard error of mean, *indicates significant differences compared to the control, "significant differences between patient groups $(p<0.05)$

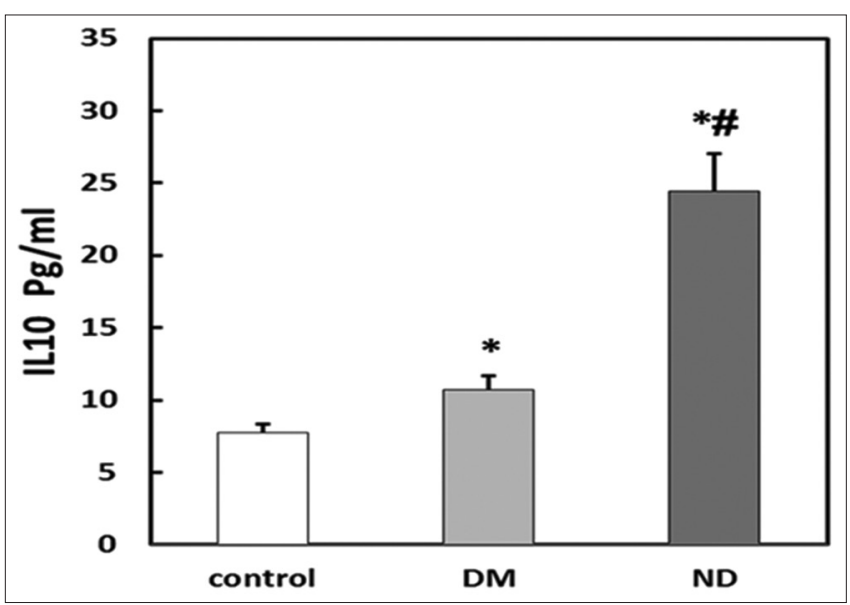

Fig. 2: Interlukine-10 levels in serum patients with type 2 diabetic, diabetic nephropathy, and control groups. Data are expressed as means \pm standard error of mean, *indicates significant differences compared to the control, "significant differences between patient groups $(p \leq 0.05)$

In diabetes mellitus, ROS are generated in different tissues by the non-enzymatic glycosylation reaction or numerous glycated proteins such as glycosylated hemoglobin, Alb, and AGEs formation [15]. Two mechanisms were suggested to explain how oxidative stress as a major factor in coupling hyperglycemia with vascular complications: first, the metabolic modifications of target tissue molecules and second, the alterations in the renal hemodynamics [16]. Increased ROS production by glomerular cells in diabetic leads to inactivate of nitric oxide effects by forming of peroxynitrite the highly reactive radicals. Peroxynitrite has direct renal cytotoxic actions, therefore renal hemodynamic was changed, and vasoconstriction occurred [17]. Recent reports suggest that oxidative damage produced by ROS has an essential role in the initiation and development of DN $[18,19]$.

A significant increase in serum IL-10 level was found in DN and T2DM groups compared to control (Fig. 2). IL-10 plays a key antiinflammatory role in the directive of the immune system and cellular activities. IL-10 effectively prevents expression and production of pro-inflammatory cytokines. T2DM is regarded as an inflammatory 


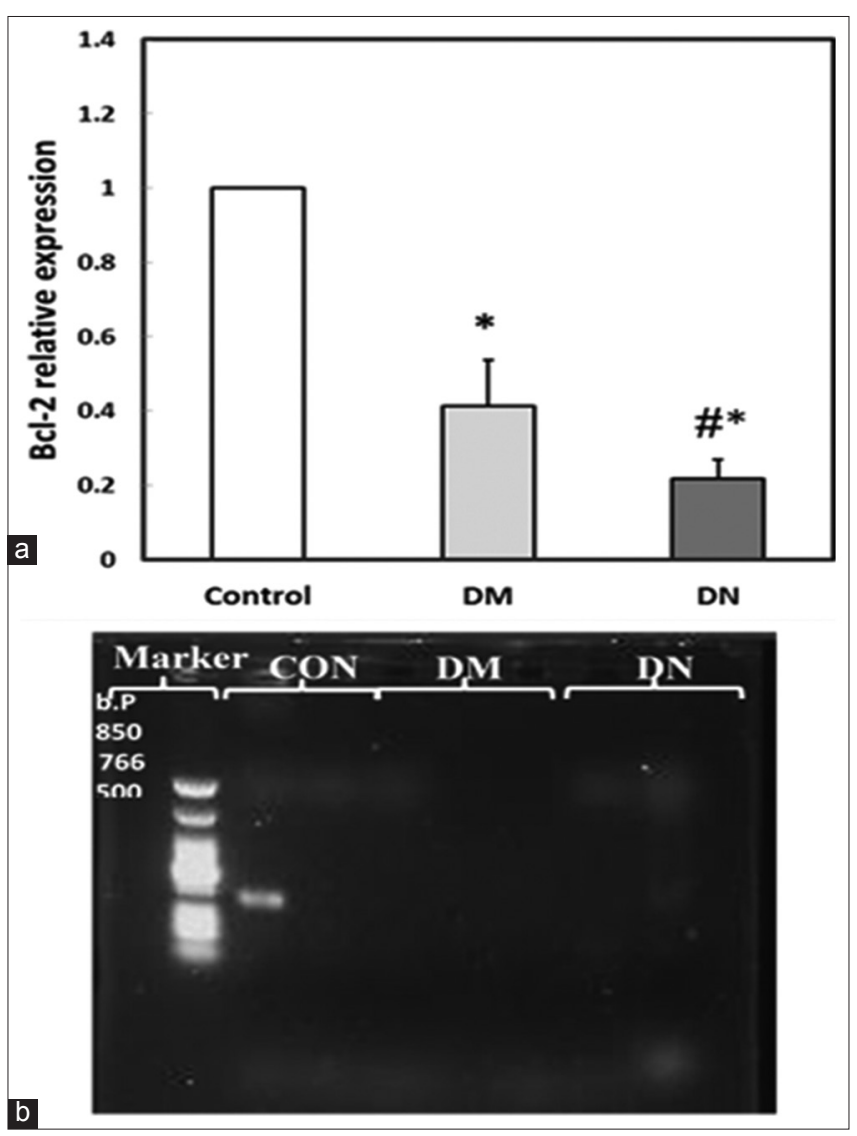

Fig. 3: (a) Bcl-2 expression in serum patients with type 2 diabetic, diabetic nephropathy, and control groups. Data are means \pm standard error of mean *indicates significant differences compared to the control, "significant differences between patient groups ( $p \leq 0.05)$. (b) Photograph of PCR products in patients groups as well as in control in $1 \%$ agarose gels confirm the product quality, bands description: (CON) Control, (DM) diabetes mellitus, (DN) diabetic nephropathy groups

disorder [20]. The higher level of circulating IL-10 may be clarified the long bearing of the disease the fairly well conserved renal function of the DN patients; furthermore, the immoderate production of IL10 in DN patients may indirectly engage the development of DN, the increased concentration of IL-10 in the serum samples from patients with DN seems to depend on the severity of the nephropathy [21]. The results of the present study are an agreement with earlier studies that demonstrated an increase in serum IL-10 level in DN patients compared to healthy subjects $[21,22]$, results suggest participation of IL-10 in the pathogenesis of DN.

The present work found apoptosis was associated with significant downregulation of the anti-apoptotic gene Bcl-2 inT2DM and DN groups compared to the control group (Fig. 3). Multiple enzymatic pathways were implicated in the generation of ROS in hyperglycemia, nicotinamide adenine dinucleotide phosphate oxidase might be an important source of ROS in diabetic kidney [23] resulting in cell death by increasing oxidative and nitrosative stress, which in turn activate the pro-apoptotic Bcl-2 protein family members and initiate the caspase pathway, apoptosis has a principal role in the pathology of mesangial cell loss related to advanced glomerulosclerosis [24]. The results of the present study are consistent with a recent study on DN state, which demonstrated an imbalance was indicated between pro and anti-apoptotic members of $\mathrm{Bcl}-2$ family through downregulation of anti-apoptotic Bcl-2 protein, and loss of expression of Bcl-2 related with the progression of renal damage in diabetes [8].

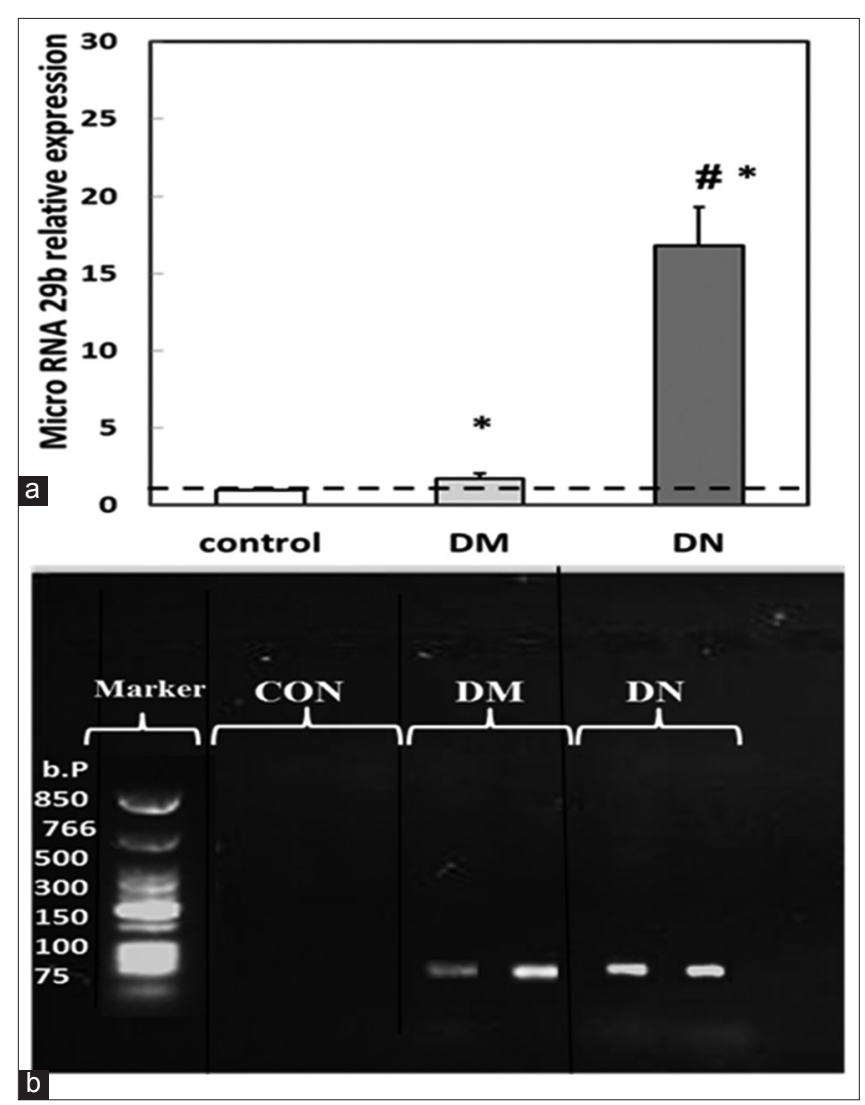

Fig. 4: (a) miRNA-29b expression in serum patients with type 2 diabetic, diabetic nephropathy, and control groups. *indicates significant differences compared to the control, \#significant differences between patient groups ( $p \leq 0.05)$. (b) Photograph of qPCR products showing miRNA $29 \mathrm{~b}$ in patients group as well as in control in $2 \%$ agarose gels confirm the product quality, bands description: (CON) Control, (DM) diabetes mellitus, (DN) diabetic nephropathy groups

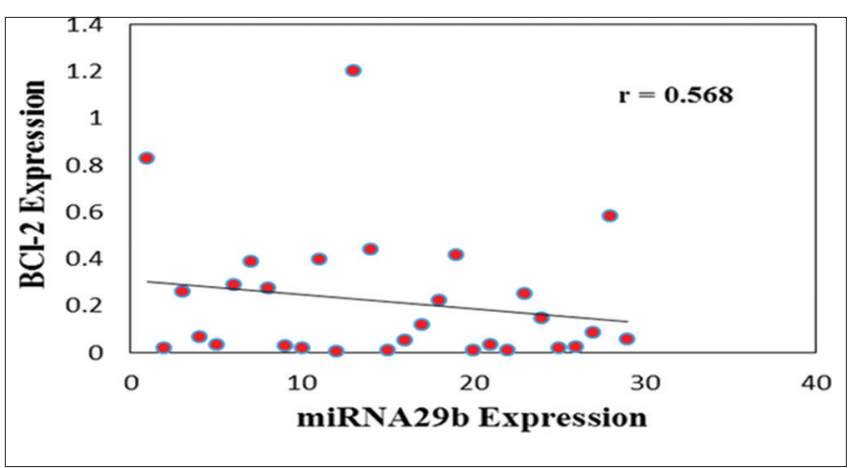

Fig. 5: Correlation between serum fold change of microR-29b and $\mathrm{BCl}-2$ relative expression in patients with diabetic nephropathy

A significant increase in serum miRNA-29b gene expression in patients with DN and T2DM compare to control group ( $\mathrm{p} \leq 0.05)$. miRNA-29b negatively regulator release of insulin by decreasing monocarboxylate transporter 1 (MCT1), MTC1 represent as a substrate for mitochondrial oxidation toward increase the cytosolic ATP:ADP ratio and promote insulin secretion in B-cells [25]. Furthermore, it has been found that miRNA-29 overexpression causes a reduction in the levels and suppresses Insig1 expression, Insig1 is an important integrator of hormonal and nutrient signals, which is stimulated by insulin [26]. The pathways of miRNA-29b included signaling of insulin, vascular endothelial growth factor signaling, cell-matrix adhesions, adherents 
junctions, tight junctions, and apoptosis pathways that are related with T2DM, most of these pathways are related to both micro and macrovascular problems in T2DM [27]. These findings were consistent with the results from Slusarza and Pulakata [13] and Peng et al. [28] who suggested miRNA-29 as a biomarker for DN. Report on rats about the high-fat diet that causing metabolism disorder indicated an increase in miRNA-29b expression and apoptosis, this confirmed by up-regulation of Cas-3 activity and decrease in Bcl-2, suggesting that miRNA-29b was enhanced endothelial permeability and apoptosis [29]. In consist of this, an inverse correlation between relative expression of miRNA-29b and anti-apoptotic Bcl-2 expression was detected in the present study (Fig. 5). Mott et al. [30] study suggested that miRNA-29b is a vital endogenous regulator, which can play an important role in endothelial cell apoptosis.

\section{CONCLUSIONS}

miRNA-29b plays an important role in hyperglycemia-induced inflammatory response by increasing ROS production which may contribute to metabolic abnormality miRNA-29b can serve as proinflammatory and modulator of the DN, subsequent enhance apoptosis by downregulation anti-apoptotic $\mathrm{Bcl}-2$ member. These findings provided new insight into the role of miRNA-29b as a biomarker and therapeutic target for DN.

\section{ACKNOWLEDGMENT}

The authors thank Dr. Ali Fawzi Abd Alsahib for his assistance in providing samples for this study, and members of the Al-Diwaniyah Teaching Hospital/Clinical Chemistry Lab.

\section{CONFLICTS OF INTEREST}

The authors declare that they have no conflicts of interest exist.

\section{AUTHORS' CONTRIBUTIONS}

Dr. Nawal Kanteel and Anwar Jalmzaiel were contributed to design and implementation of the research, to the analysis of the results and to the writing of the manuscript with support from Dr. Ferdous Abaas Jaber. All authors approved the final version for submission.

\section{REFERENCES}

1. Groop PH, Thomas MC, Moran JL, Wadèn J, Thorn LM, Mäkinen VP, et al. The presence and severity of chronic kidney disease predicts allcause mortality in Type 1 diabetes. Diabetes 2009;58:1651-8.

2. Tervaert TW, Mooyaart AL, Amann K, Cohen AH, Cook HT, Drachenberg $\mathrm{CB}$, et al. Pathologic classification of diabetic nephropathy. J Am Soc Nephrol 2010;21:556-63.

3. Mohammad JI, Chigrupati S, Othman AS, Iqbal MZ. Diabetes nephropathy an obvious complication in long term Type 1 diabetes mellitus: A case study. Asian J Pharm Clin Res 2017;10:4-7.

4. Haghighatpanah GT, Jha A, Mallayasamy S. Study on prescribing pattern of anti-diabetic drugs among Type 2 diabetes patients with complication in South Indian teaching hospital. Asian J Pharm Clin Res 2016;9 Suppl 1:194-7.

5. Mosser DM, Zhang X. Interleukin-10: New perspectives on an old cytokine. Immunol Rev 2008;226:205-18.

6. Skommer J, Wlodkowic D, Deptala A. Larger than life: Mitochondria and the bcl-2 family. Leuk Res 2007;31:277-86.

7. Verzola D, Bertolotto MB, Villaggio B, Ottonello L, Dallegri F, Frumento G, et al. Taurine prevents apoptosis induced by high ambient glucose in human tubule renal cells. J Investig Med 2002;50:443-51.

8. Hotchkiss RS, Strasser A, McDunn JE, Swanson PE. Cell death.
N Engl J Med 2009;361:1570-83

9. Cho MH. Renal fibrosis. Korean J Pediatr 2010;53:735-40.

10. Kozomara A, Griffiths-Jones S. MiRBase: Integrating microRNA annotation and deep-sequencing data. Nucleic Acids Res 2011;39:D152-7.

11. Samuel VT, Shulman GI. Mechanisms for insulin resistance: Common threads and missing links. Cell 2012;148:852-71.

12. Kriegel AJ, Liu Y, Fang Y, Ding X, Liang M. The miR-29 family: Genomics, cell biology, and relevance to renal and cardiovascular injury. Physiol Genomics 2012;44:237-44.

13. Ślusarz A, Pulakat L. The two faces of miR-29. J Cardiovasc Med (Hagerstown) 2015;16:480-90.

14. Long J, Wang Y, Wang W, Chang BH, Danesh FR. MicroRNA-29c is a signature microRNA under high glucose conditions that targets sprouty homolog 1, and its in vivo knockdown prevents progression of diabetic nephropathy. J Biol Chem 2011;286:11837-48.

15. Kaneto H, Katakami N, Matsuhisa M, Matsuoka TA. Role of reactive oxygen species in the progression of Type 2 diabetes and atherosclerosis. Mediators Inflamm 2010;2010:453892.

16. Miranda-Díaz AG, Pazarín-Villaseñor L, Yanowsky-Escatell FG, Andrade-Sierra J. Oxidative stress in diabetic nephropathy with early chronic kidney disease. J Diabetes Res 2016;2016:7047238.

17. Schoonmaker GC, Fallet RW, Carmines PK. Superoxide anion curbs nitric oxide modulation of afferent arteriolar ANG II responsiveness in diabetes mellitus. Am J Physiol Renal Physiol 2000;278:F302-9.

18. Brownlee $M$. The pathobiology of diabetic complications: A unifying mechanism. Diabetes 2005;54:1615-25.

19. Rao C, Rao S, Prasad KH, Vidya B. Catalase and malondialdehyde levels: Possible markers for Type 2 diabetes mellitus. Euro J Biomed Pharm Sci 2017;4:232-7.

20. Donath MY, Shoelson SE. Type 2 diabetes as an inflammatory disease. Nat Rev Immunol 2011;11:98-107.

21. Myśliwska J, Zorena K, Semetkowska-Jurkiewicz E, Rachoń D, Suchanek H, Myśliwski A, et al. High levels of circulating interleukin-10 in diabetic nephropathy patients. Eur Cytokine Netw 2005;16:117-22.

22. Bakheet MS. Interleukin 10 gene polymorphisms and susceptibility to nephropathy in Egyptian diabetic patients. Int J Biochem Res Rev 2017; $17: 1-11$

23. Gill PS, Wilcox CS. NADPH oxidases in the kidney. Antioxid Redox Signal 2006;8:1597-607.

24. Sugiyama H, Kashihara N, Makino H, Yamasaki Y, Ota A. Apoptosis in glomerular sclerosis. Kidney Int 1996;49:103-11.

25. Pullen TJ, da Silva Xavier G, Kelsey G, Rutter GA. MiR-29a and miR-29b contribute to pancreatic beta-cell-specific silencing of monocarboxylate transporter 1 (Mct1). Mol Cell Biol 2011;31:3182-94.

26. Vikman J, Ma X, Hockerman GH, Rorsman P, Eliasson L. Antibody inhibition of synaptosomal protein of $25 \mathrm{kDa}$ (SNAP-25) and syntaxin 1 reduces rapid exocytosis in insulin-secreting cells. J Mol Endocrinol 2006;36:503-15.

27. Shin ES, Sorenson CM, Sheibani N. Diabetes and retinal vascular dysfunction. J Ophthalmic Vis Res 2014;9:362-73.

28. Peng H, Zhong M, Zhao W, Wang C, Zhang J, Liu X, et al. Urinary miR-29 correlates with albuminuria and carotid intima-media thickness in Type 2 diabetes patients. PLoS One 2013;8:e82607.

29. Zhu HQ, li Q, Dong LY, Zhou Q, Wang H, Wang Y, et al. MicroRNA-29b promotes high-fat diet-stimulated endothelial permeability and apoptosis in apoE knock-out mice by down-regulating MT1 expression. Int J Cardiol 2014;176:764-70.

30. Mott JL, Kobayashi S, Bronk SF, Gores GJ. Mir-29 regulates mcl-1 protein expression and apoptosis. Oncogene 2007;26:6133-40. 